\title{
Factors Associated with Hookah Smoking among University Students
}

\author{
Hamid Joveini ${ }^{1}$, Taherh Dehdari ${ }^{2}$, Hassan Eftekhar Ardebili ${ }^{3}$, Mahmoud Mahmoudi ${ }^{4}$, Ali Asghar Firouzian ${ }^{5}$, \\ Alireza Rohban ${ }^{6}$
}

${ }^{1}$ Ph.D. Candidate in Health Education and Promotion, Faculty of Public Health, Tehran University of Medical Sciences, Tehran, Iran

${ }^{2}$ Assistant Professor of Health Education, Department of Health Education and Promotion, School of Health, Iran University of Medical Sciences, Tehran, Iran

${ }^{3}$ Professor, Department of Health Education and Promotion, School of Public Health, Tehran University of Medical Sciences, Tehran, Iran

${ }^{4}$ Professor, Department of Biostatistics, School of Public Health, Tehran University of Medical Sciences, Tehran Iran

${ }^{5}$ M.Sc. in Nursing, Educator, Esfarayan University of Medical Sciences, Esfarayen, Iran

${ }^{6}$ M.Sc. in Rehabilitation Management, School of Rehabilitation, Iran University of Medical Sciences, Tehran, Iran

\section{Type of article: Original}

\begin{abstract}
Background: These days, hookah smoking has gained popularity among people in many communities, especially among youths and students, and more attention to this issue seems necessary. The purpose of this study was to determine the factors affecting hookah smoking among Sabzevar Azad University students.

Methods: This cross-sectional study was conducted on university students in Sabzevar, Iran in 2014. The questionnaire was developed and its validity and reliability were assessed. Three hundred six male students of Sabzevar Azad University were selected by simple random sampling and questionnaires were filled out by them. The collected data were analyzed by SPSS software and the Chi-Square and Independent-samples t-test.

Results: The results showed that $47.7 \%$ of the participants had a history of smoking hookah. The main factors affecting hookah smoking from participants' point of view were: filling leisure time, availability of hookah, positive social appearance, friends' invitation and relief from anxieties. Chi-Square tests showed that there was no significant relationship between fathers' level of education ( $\mathrm{p}=0.41)$, mothers' level of education $(\mathrm{p}=0.46)$, fathers' job $(\mathrm{p}=0.18)$, mothers' job $(\mathrm{p}=0.53)$ and students' current grade $(\mathrm{p}=0.41)$ with hookah smoking. The study showed significant relationship between present hookah smoking and awareness about complications of the hookah $(\mathrm{p}=0.01)$.

Conclusion: Interventions to reduce and quit hookah smoking among students should include several items, such as teaching problem-solving skills to fill leisure time properly and to deal with the temptation of hookah smoking, as well as teaching refusal skills at the invitation of friends for hookah.
\end{abstract}

Keywords: Leisure time, Hookah smoking, Students

\section{Introduction}

For four centuries the hookah has been used for smoking tobacco, by people in Asia and Africa (1). The origins of the hookah are from ancient Iran and India (2). Hookah smoking has gained popularity in many communities, especially among young adults and students (3). Hookah smoking in the eastern Mediterranean is mainly a social activity which happens mostly in groups (2). In some public places such as cafés, the traditional restaurant or the teahouse, flavored hookah is being served, and families usually have no negative attitude towards it $(3,4)$. The

\section{Corresponding author:}

Professor Hassan Eftekhar Ardebili, Department of Health Education and Promotion, School of Public Health, Tehran University of Medical Sciences, Tehran, Iran.

Tel: +98.9102121046, Fax:+98.216462267, Email: eftkhara@sina.tums.ac.ir

Received: July 15, 2016, Accepted: October 22, 2016, Published: December 2016

iThenticate screening: October 22, 2016, English editing: November 14, 2016, Quality control: November 25, 2016

(C) 2016 The Authors. This is an open access article under the terms of the Creative Commons Attribution-NonCommercialNoDerivs License, which permits use and distribution in any medium, provided the original work is properly cited, the use is non-commercial and no modifications or adaptations are made. 
increase in popularity of hookah smoking is due to various reasons, such as the social context of its usage (among friends and in public places), the appeal of fruity flavors and a misconception that it is less harmful than cigarettes $(3,5)$. One of the most important reasons for the daily increase of hookah smoking, and its popularity among youths is its flavored tobacco, which is produced in Bahrain and Egypt (6), and has spread throughout the eastern Mediterranean region since 1990. These tobaccos contain flavored ingredients that create mild and scented smoke which covers the offensive smell of smoke $(7,8)$. Many hookah smokers think that hookah is less addictive and has less nicotine compared to cigarettes $(3,9,10)$, whereas it has more smoke and nicotine. The amount of blood nicotine of daily hookah smokers is equivalent to people who smoke ten cigarettes a day (11). The World Health Organization, in a statement has declared that hookah smoking is a new challenge in public health (12). The smoke from tobacco contains a high level of toxic chemicals such as carbon monoxide, heavy metals, and carcinogens (13) which are associated with diseases such as lung cancer, respiratory diseases, cardiovascular diseases as well as low weight of newborn babies (14). Also, a shared hookah mouthpiece can cause the spread of infectious diseases such as tuberculosis, herpes, flu and hepatitis (10). The highest rate of hookah smoking is in the eastern Mediterranean region and southeast of Asia (15). According to a study performed in the eastern Mediterranean region, the prevalence of hookah smoking among youths in this region has increased more than cigarettes $(16,17)$. In addition to the eastern Mediterranean region, the prevalence of hookah smoking has also increased in other regions such as the United States and European countries (18). In the United States, hookah smoking has become the second most common type of tobacco usage after cigarette $(19,20)$. In Iran, a study carried out in Tehran revealed that $27 \%$ of high school students smoke hookah (21). Also, in another similar study done by Roohafza and colleagues, $28 \%$ of hookah usage among students was reported (22). Many other studies state that other countries are facing the same problem of hookah smoking, such as the rate of hookah smoking among university students in Saudi Arabia, Pakistan, and England which were reported as 37, 54 and 38 percent respectively (23-25). It is believed that the use of the hookah will potentially lead to cigarette use. University students are at greater risk of a tendency toward using tobacco due to its easy access, having a relationship with close friends who smoke hookah and dealing with various emotional, social and educational challenges (27). Therefore, knowing their aspects of behavior on a tendency to hookah smoking seems necessary. So, to determine the factors affecting hookah smoking, this study has been carried out among male students of Sabzevar Azad University in 2014.

\section{Material and Methods}

This cross-sectional study was performed on 306 male students of Sabzevar Azad University in 2014. First, five hookah smoking students were interviewed about the factors affecting hookah smoking and their different attitudes toward it. Then, the questionnaire was designed according to research goals. The questionnaire was provided in two parts. The first part was about the demographic factors (20 questions) and the second part was about the factors affecting first time use of the hookah (8 questions), factors affecting current use of the hookah (17 questions) and awareness about the harms of hookah smoking (6 questions). Additionally, two questions about hookah smoking in present (Yes or No) and the number of time smoking were also included in the questionnaire. After preparing the questionnaire, it was given to ten students and their correcting opinions were applied in the questionnaire. Reliability and validity of the questionnaire were evaluated with test-retest method and content validity method by a group of experts. The Spearman correlation coefficient obtained from retest (with 20 students filling out the questionnaire 2 times with 10 days space) for questions about the reasons of smoking hookah $(\mathrm{r}=0.81 \mathrm{p}=0.003)$, for questions about the reasons of smoking hookah for the first time $(r=0.70 \mathrm{p}=0.02)$ and for questions about the awareness of harms of smoking hookah $(\mathrm{r}=0.90 \mathrm{p}=0.0001)$ was significant. The sampling method was simple random sampling and 306 male students of Sabzevar Azad University agreed to fill out the questionnaire. The inclusion criteria were students' agreement to fill out the questionnaire and studying in Sabzevar Azad University and theexclusion criteria were the lack of inclination to participate in the study and incomplete questionnaires. Subsequently, the questionnaires were given to the students. The students were assured about the confidentiality of their personal information and their agreement to enter the study was obtained, meanwhile, there was a possibility that if a student didn't want to fill and return the questionnaire, they could leave the study. Fortunately, this case was not observed in the study. The data collected were analyzed by IBM@ SPSSC Statistics version 21 (IBM@ Corp., Armonk, NY, USA). To determine the relationship between quantitative variables of age and number of siblings with current hookah smoking (yes and no), Independent sample $\mathrm{T}$ test was used. To determine the relationship between current hookah smoking with parents' level of education and job and the students' current grade, Chi-Square was used. To determine the difference between students' mean score of awareness about harms of hookah and current smoking of hookah, an independentsamples t-test was used. In addition, to determine the relationship between current hookah smoking and current cigarette smoking, the Chi-Square was used. In this study, the significance level was considered $\mathrm{p}<0.05$. 


\section{Results}

The mean age of the participants was 22.4 years $( \pm 2.5)$, the youngest participant was 18 and the oldest was 34 . The fathers' level of education in $33.4 \%$ of the participants was university education, in $19.5 \%$ of the participants was high school education and in other participants was less than junior school education. The mothers' level of education in $21.8 \%$ of the participants was university education, in $19 \%$ of the participants was high school education and in other participants was less than junior school education. $30.5 \%$ of the fathers were employees, $45 \%$ were self-employed, $14.2 \%$ were retired, $7.6 \%$ were laborers and $2.6 \%$ were unemployed while $79.7 \%$ of mothers were unemployed and $13 \%$ were employees. Sixty Nine percent of the participants were undergraduate students and $27.5 \%$ were associate level students. Chi-Square tests showed that there was no significant relationship between fathers' level of education (0.41), mothers' level of education (0.46), fathers' job (0.18), mothers' job (0.53) and students' current grade $(0.41)$ with hookah smoking. Forty Seven percent $(n=143)$ of the participants stated that they smoke hookah and $53.1 \%(\mathrm{n}=162)$ stated that they don't. Hookah smoking among the participants was mostly a daily routine $(25.7 \%)$ or weekly $(25 \%)$. The mean age that hookah smoking had begun among hookah smoking participants was $17.9( \pm 2.5) .37 .4 \%$ of the participants had smoked hookah in recreation centers and $39.6 \%$ in traditional cafés and restaurants. $54.2 \%$ of the participants reported that the first time they smoked hookah, they were with friends. $68.5 \%$ of the participants reported that no one in their family smokes the hookah. $16.6 \%$ of the participants were cigarette smokers as well. The Chi-Square test showed no significant relationship between hookah smoking and cigarette smoking $(\mathrm{p}=0.2)$. Results also showed the significant relationship between present hookah smoking and awareness about complications of hookah $(\mathrm{p}=0.01)$. Main reasons for hookah smoking for the first time, from the students' point of view were: obtaining new experience, relaxation, and communication with others. The important reasons expressed by students for continuing to smoke hookah were: filling leisure time, availability, a more positive social appearance than cigarette smoking, and anxiety reduction.

\section{Discussion}

The findings of this study showed that the prevalence of hookah smoking among the students ( $n=143$ ) was $46.9 \%$. In another similar study carried out in Iran by Roohafza and colleagues, the prevalence of hookah smoking was reported as $28 \%$ (22). Other studies in other countries also show a high prevalence of hookah smoking, and that prevalence among students of Saudi Arabia, Pakistan, and England was reported 37, 54 and 38 percent respectively (23-25). The increase in the prevalence of hookah smoking in our study could be related to students' lack of knowledge regarding the harms of hookah smoking, lack of appropriate leisure time due to the shortage of cultural and sports programs of the university, lack of family control due to the distance between students and their families and living in rental houses, therefore, diverse cultural and sports programs and systematic education programs about the harms of hookah smoking for students and families, can lead to a significant reduction in hookah smoking. The result of this study showed that the starting age of hookah smoking is between 10 and 24 years with a mean age of 17.9 years. Consistent with this study, a study carried out in Qatar in 2016 by Jam and colleagues, reported the starting age as between 13 and 22 years (28). In another study, the mean age was reported as 12 years (29). Starting hookah smoking at early ages could be due to lack of knowledge about the harms of hookah smoking, the appeal of flavored tobacco and better social acceptance in family and society compared to cigarette smoking, and in a study carried out in Lebanon, individuals aged 5 to 18 years of age had their first experience of hookah smoking among their family members (30). Considering the hookah as a bridge to other tobacco products, reduction in the starting age of hookah smoking could encourage teenagers to lookto other addictive substances, and also be exposed to toxic chemicals of hookah for a long time and consequently, the occurring diseases related to them; there fore to prevent tobacco addiction and to enhance necessary skills in order to avoid using addictive substances, it is recommended to perform related education programs in schools. The students stated that the first time they smoked hookah was in tea houses and recreation centers respectively. In a study of Maziak and colleagues in Syria, hookah smoking by youths was mainly done out of the house and for the purpose of passing leisure time (31). Other studies also indicate that increases in the prevalence of hookah smoking in recent decades is due to the existence of traditional restaurants and cafés $(32,33)$ and that is because of an increase in accessibility of hookah in public places $(3,34)$. Obvious policies to deal with hookah suppliers and to increase taxes on tobacco products has a considerable impact on reducing hookah smoking, especially among the youth. Consistent with other studies $(35,36)$, the present study demonstrates the increase in the prevalence of hookah smoking compared with cigarettes (46.9 vs. 16.6). According to various studies, it is due to a misconception that hookah smoking is less harmful compared to cigarettes $(37,38)$. Another possible reason could be that the hookah is more sociably accepted compared to cigarettes (39). Therefore, it seems necessary to change people's misconceptions about the harms of hookah smoking and to promote the culture of usage in the community. Based on the findings of our study, the most important reasons for hookah smoking, from the students' point of view, were respectively: filling leisure time, availability of hookah, friends' request, and 
positive social appearance. In a Primark study, the social acceptance and availability were the most important reasons of hookah smoking by youths (9). In another study, filling leisure time was considered as the most important challenge to quit hookah smoking (28). So, having plans to fill the student's leisure time through cultural and sports programs in university, and to teach some skills to cope with the temptation of hookah smoking in order to prevent students' tendency to hookah smoking, seems essential. This study showed that $54.2 \%$ of students had their first experience of hookah smoking with friends. In a study carried out among Canadian and English students, relaxing with friends was mentioned as an important factor in hookah smoking (40). In their study, Asfar and colleagues reported that about $80.2 \%$ of people had their first experience of hookah smoking with their friends and in comparison with hookah smokers in cafés, students are more likely to smoke hookah with their friends (39). Therefore, families' role in the control of children's relationships and awareness about children's leisure time is very momentous. Youths can benefit from having good problem-solving skills especially while facing others' invitations to smoke, so teaching problem-solving skills in school, such as how to say no to friends in response to smoking, seems necessary. In this study, $95.7 \%$ of students used flavored tobacco. In the study carried out in Syria by Maziak and colleagues, it was reported that scented tobacco has an important role in popularity and increase of hookah smoking among youths (26). According to some studies, one of the reasons for this increase would be people's misconception about the safety of scented tobacco compared to natural tobacco and also the concealment of odors by these tobaccos $(41,42)$. Therefore, due to the daily increase of using flavored tobacco and its popularity among youths, more studies are needed to determine the effects and harms of these products and additives, on people's health. This study shows the significant relationship between the mean knowledge about harms of hookah smoking and hookah smoking $(\mathrm{p}=0.013)$. Another study indicates that one reason for high usage of hookah in developing countries is a lack of knowledge about its harms and negative outcomes. (43). Despite the lack of knowledge about harms of hookah smoking, misconceptions about hookah smoking is another major reason for high usage of hookah in society (40), so, students should be aware of the numerous harms of hookah smoking and their misconceptions should be corrected. Self-report information, lack of comparison among different universities, and lack of study on female students were some of our study limitations, therefore, for future studies, it is recommended to compare the prevalence of hookah smoking in both genders.

\section{Conclusions}

The results of this study showed the high prevalence of hookah smoking among students due to different reasons including; filling leisure time, availability, more positive social appearance than cigarette smoking, anxiety reduction, and obtaining a new experience. The practical significance of these findings is that to prevent the increase in hookah smoking among students, some factors should be underlined including; misconception correction, planning various entertaining programs to fill students' leisure time, cultural and sports program developments in universities, and problem-solving skills development for anxiety reduction. An interventional research in the topic of hookah smoking withdrawal among students and factors affecting it, could be the right direction for future research on this topic.

\section{Acknowledgments:}

This study is a part of the Ph.D. thesis entitled "The effect of an empowerment program based on Theory of Planned Behavior (TPB) and Health Action Process Approach (HAPA) for smoking water pipe cessations among college students" approved by Tehran University of Medical Sciences in 2015. The authors would like to thank the cooperation and efforts of staff and students of Islamic Azad University of Sabzevar.

\section{Conflict of Interest:}

There is no conflict of interest to be declared.

Authors' contributions:

All authors contributed to this project and article equally. All authors read and approved the final manuscript.

\section{References:}

1) Chattopadhyay A. Emperor Akbar as a healer and his eminent physicians. Bull Indian Inst Hist Med Hyderabad. 2000; 30(2): 151-7. PMID: 12577995.

2) Chaaya M, El Roueiheb Z, Chemaitelly H, Azar G, Nasr J, Al-Sahab B. Argileh smoking among university students: a new tobacco epidemic. Nicotine Tob Res. 2004; 6(3): 457-63. doi: 10.1080/14622200410001696628. PMID: 15203779. 
3) Ward KD, Eissenberg T, Gray JN, Srinivas V, Wilson N, Maziak W. Characteristics of US waterpipe users: a preliminary report. Nicotine Tob Res. 2007; 9(12): 1339-46. doi: 10.1080/14622200701705019. PMID: 18058352.

4) Maziak W, Fouad FM, Asfar T, Hammal F, Bachir EM, Rastam S, et al. Prevalence and characteristics of narghile smoking among university students in Syria. Int J Tuberc Lung Dis. 2004; 8(7): 882-9. PMID: 15260281.

5) Chan A, Murin S. Up in smoke: the fallacy of the harmless Hookah. Chest. 2011; 139(4): 737-8. doi: 10.1378/chest.10-2985. PMID: 21467052.

6) Jasim S, Kadhim L, El-Awa F, Fouad H, Warren C, Lee J, et al. Tobacco use among students aged 13-15 years-Baghdad, Iraq, 2008. Morbidity and Mortality Weekly Report. 2009; 58(12): 305-8.

7) Rastam S, Ward KD, Eissenberg T, Maziak W. Estimating the beginning of the waterpipe epidemic in Syria. BMC public Health. 2004; 4: 32. doi: 10.1186/1471-2458-4-32. PMID: 15294023, PMCID: PMC514554.

8) Maziak W. The waterpipe: time for action. Addiction. 2008; 103(11): 1763-7. doi: 10.1111/j.13600443.2008.02327.x. PMID: 18778388, PMCID: PMC2588474.

9) Primack BA, Sidani J, Agarwal AA, Shadel WG, Donny EC, Eissenberg TE. Prevalence of and associations with waterpipe tobacco smoking among US university students. Ann Behav Med. 2008; 36(1): 81-6. doi: 10.1007/s12160-008-9047-6. PMID: 18719977, PMCID: PMC3004534.

10) Prevention CfDCa. Fact sheet on hookah smoking. 2011.

11) Neergaard J, Singh P, Job J, Montgomery S. Waterpipe smoking and nicotine exposure: a review of the current evidence. Nicotine Tob Res. 2007; 9(10): 987-94. doi: 10.1080/14622200701591591. PMID: 17943617, PMCID: PMC3276363.

12) Organization WH, Regulation WSGoTP. Advisory note: waterpipe tobacco smoking: health effects, research needs and recommended actions by regulators-2nd ed: World Health Organization. 2015.

13) Maziak W, Ward KD, Afifi Soweid RA, Eissenberg T. Tobacco smoking using a waterpipe: a re-emerging strain in a global epidemic. Tob Control. 2004; 13(4): 327-33. doi: 10.1136/tc.2004.008169. PMID: 15564614, PMCID: PMC1747964.

14) Knishkowy B, Amitai Y. Water-pipe (narghile) smoking: an emerging health risk behavior. Pediatrics. 2005; 116(1): e113-e9.

15) Shihadeh A, Azar S, Antonios C, Haddad A. Towards a topographical model of narghile water-pipe café smoking: a pilot study in a high socioeconomic status neighborhood of Beirut, Lebanon. Pharmacol Biochem Behav. 2004; 79(1): 75-82. doi: 10.1016/j.pbb.2004.06.005. PMID: 15388286.

16) Elawa F, Warren C, Jones N. Changes in tobacco use among 13-15-year-olds between 1999 and 2007: findings from the Eastern Mediterranean Region. 2010; 16(3).

17) Warren CW, Lea V, Lee J, Jones NR, Asma S, McKenna M. Change in tobacco use among 13-15 year olds between 1999 and 2008: findings from the Global Youth Tobacco Survey. Glob Health Promot. 2009; 16(2 suppl): 38-90. doi: 10.1177/1757975909342192. PMID: 19770234.

18) Shafagoj YA, Mohammed FI. Levels of maximum end-expiratory carbon monoxide and certain cardiovascular parameters following hubble-bubble smoking. Saudi Med J. 2002; 23(8): 953-8. PMID: 12235470 .

19) Cobb CO, Khader Y, Nasim A, Eissenberg T. A multiyear survey of waterpipe and cigarette smoking on a US university campus. J Am Coll Health. 2012; 60(7): 521-7. doi: 10.1080/07448481.2012.692416. PMID: 23002800, PMCID: PMC4487802.

20) Primack BA, Shensa A, Kim KH, Carroll MV, Hoban MT, Leino EV, et al. Waterpipe smoking among US university students. Nicotine Tob Res. 2013; 15(1): 29-35. doi: 10.1093/ntr/nts076. PMID: 22641433, PMCID: PMC3524056.

21) Momenan A, Sarbandi ZF, Etemadi A, Azizi F. Pattern of waterpipe (ghalyan) use among intermediate and high school students: a cross-sectional study in Tehran, Iran. Payesh. 2007; 6(2): 135-44.

22) Roohafza H, Sadeghi M, Shahnam M, Bahonar A, Sarafzadegan N. Perceived factors related to cigarette and waterpipe (ghelyan) initiation and maintenance in university students of Iran. Int J Public Health. 2011; 56(2): 175-80. doi: 10.1007/s00038-009-0107-x. PMID: 20020176.

23) Jackson D, Aveyard P. Waterpipe smoking in students: prevalence, risk factors, symptoms of addiction, and smoke intake. Evidence from one British university. BMC public health. 2008; 8: 174. doi: 10.1186/1471-2458-8-174. PMID: 18498653, PMCID: PMC2413225. 
24) Jawaid A, Zafar AM, Rehman TU, Nazir MR, Ghafoor ZA, Afzal O, et al. Knowledge, attitudes and practice of university students regarding waterpipe smoking in Pakistan. Int J Tuberc Lung Dis. 2008; 12(9): 1077-84. PMID: 18713508.

25) Mandil A, BinSaeed A, Ahmad S, Al-Dabbagh R, Alsaadi M, Khan M. Smoking among university students: a gender analysis. Journal of infection and public health. 2010; 3(4): 179-87. doi: 10.1016/j.jiph.2010.10.003. PMID: 21126722.

26) Maziak W. The global epidemic of waterpipe smoking. Addict Behav. 2011; 36(1-2): 1-5. doi: 10.1016/j.addbeh.2010.08.030. PMID: 20888700, PMCID: PMC4135081.

27) Halperin AC, Smith SS, Heiligenstein E, Brown D, Fleming MF. Cigarette smoking and associated health risks among students at five universities. Nicotine Tob Res. 2010; 12(2): 96-104. doi: 10.1093/ntr/ntp182. PMID: 20018947, PMCID: PMC2902913.

28) Jaam M, Al-Marridi W, Fares H, Izham M, Kheir N, Awaisu A. Perception and intentions to quit among waterpipe smokers in Qatar: a cross-sectional survey. Public health action. 2016; 6(1): 38-43. doi: 10.5588/pha.15.0054. PMID: 27051611, PMCID: PMC4809728.

29) Tamim H, Al-Sahab B, Akkary G, Ghanem M, Tamim N, Roueiheb Z, et al. Cigarette and nargileh smoking practices among school students in Beirut, Lebanon. Am J Health Behav. 2007; 31(1): 56-63. doi: 10.5993/AJHB.31.1.6. PMID: 17181462.

30) Martinasek MP, McDermott RJ, Martini L. Waterpipe (hookah) tobacco smoking among youth. Current problems in pediatric and adolescent health care. 2011; 41(2): 34-57. doi: 10.1016/j.cppeds.2010.10.001. PMID: 21232693.

31) Maziak W, Eissenberg T, Ward KD. Patterns of waterpipe use and dependence: implications for intervention development. Pharmacol Biochem Behav. 2005; 80(1): 173-9. doi: 10.1016/j.pbb.2004.10.026. PMID: 15652393.

32) Al Mulla A, Fanous N, Seidenberg AB, Rees VW. Secondhand smoke emission levels in waterpipe cafes in Doha, Qatar. Tobacco control. 2015; 24(e3): e227-e31. doi: 10.1136/tobaccocontrol-2014-051717.

33) Klein JD. Hookahs and waterpipes: cultural tradition or addictive trap? Journal of Adolescent Health. 2008; 42(5): 434-5. doi: 10.1016/j.jadohealth.2008.02.006. PMID: 18407037.

34) Barnett TE, Curbow BA, Weitz JR, Johnson TM, Smith-Simone SY. Water pipe tobacco smoking among middle and high school students. American Journal of Public Health. 2009; 99(11): 2014-9. doi: 10.2105/AJPH.2008.151225. PMID: 19762667, PMCID: PMC2759787.

35) Al-Kuwari M. Tobacco control in Qatar. Middle East J Fam Med. 2008; 6(6): 11-3.

36) Moh' d Al - Mulla A, Abdou Helmy S, Al - Lawati J, Al Nasser S, Ali Abdel Rahman S, Almutawa A, et al. Prevalence of Tobacco Use Among Students Aged 13 - 15 Years in Health Ministers' Council/Gulf Cooperation Council Member States, 2001 - 2004. J Sch Health. 2008; 78(6): 337-43. doi: 10.1111/j.17461561.2008.00311.x. PMID: 18489467.

37) Aljarrah K, Ababneh ZQ, Al-Delaimy WK. Perceptions of hookah smoking harmfulness: predictors and characteristics among current hookah users. Tob Induc Dis. 2009; 5(1): 16. doi: 10.1186/1617-9625-5-16. PMID: 20021672, PMCID: PMC2806861.

38) Shihadeh A. Investigation of mainstream smoke aerosol of the argileh water pipe. Food Chem Toxicol. 2003; 41(1): 143-52. doi: 10.1016/S0278-6915(02)00220-X. PMID: 12453738.

39) Asfar T, Ward KD, Eissenberg T, Maziak W. Comparison of patterns of use, beliefs, and attitudes related to waterpipe between beginning and established smokers. BMC public health. 2005; 5: 19. doi: 10.1186/1471-2458-5-19. PMID: 15733316, PMCID: PMC553967.

40) Roskin J, Aveyard P. Canadian and English students' beliefs about waterpipe smoking: a qualitative study. BMC public health. 2009; 9: 10. doi: 10.1186/1471-2458-9-10. PMID: 19134220, PMCID: PMC2628878.

41) Khalil J, Heath RL, Nakkash RT, Afifi RA. The tobacco health nexus? Health messages in narghile advertisements. Tobacco Control. 2009; 18(5): 420-1. doi: 10.1136/tc.2009.030148. PMID: 19779065.

42) Smith-Simone S, Maziak W, Ward KD, Eissenberg T. Waterpipe tobacco smoking: knowledge, attitudes, beliefs, and behavior in two US samples. Nicotine Tob Res. 2008; 10(2): 393-8. doi: 10.1080/14622200701825023. PMID: 18236304, PMCID: PMC3215239.

43) Prignot JJ, Sasco AJ, Poulet E, Gupta PC, Aditama TY. Alternative forms of tobacco use. Int J Tuberc Lung Dis. 2008; 12(7): 718-27. PMID: 18544194. 